\title{
The Dynamic Market-Derived Capital Pricing Model: Theoretical Foundations and Empirical Analysis
}

\author{
Chaouki Mouelhi ${ }^{1}$ and Jacques Saint-Pierre ${ }^{2}$
}

\begin{abstract}
In this paper we propose a dynamic version of the Market-Derived Capital Pricing Model (MCPM) of McNulty, Yeh, Schulze and Lubatkin (2002).By introducing the competitive advantage period "CAP" in the algorithm of this model, we develop the Dynamic Market-Derived Capital Pricing Model (DMCPM). The economic theoretical foundation of the DMCPM is based on the competitive economic equilibrium concept. A sample of 80 U.S. firms and cross section data are used in the empirical analysis. We compare the cost of capital estimation results from the DMCPM with those from the CAPM. Also, we test the explanatory power of the marginal return to cost of capital ratio from the DMCPM compared to that from the CAPM. The results of difference tests, Cox tests and J tests of Davidson and MacKinnon (1981) show the relevance of the estimated cost of capital from the DMCPM.
\end{abstract}

JEL classification numbers: G12, G30, C52

Keywords: Cost of equity, Cost of capital, competitive advantage period, capital asset pricing model

\section{Introduction}

The cost of capital is a key concept in modern financial theory. Indeed, the cost of capital is the major link between investment decisions and financing decisions. In addition, it is a fundamental concept in strategic decisions such as new securities issues, corporate restructuring, mergers and acquisitions. Moreover, the cost of capital is essential in managing for value in governance systems and performance evaluation based on measures such as economic value added. In all cases, an accurate measure of the cost of capital is essential.

\footnotetext{
${ }^{1}$ University of Quebec at Rimouski, Quebec, Canada.

${ }^{2}$ Laval University, Quebec, Canada.

Article Info: Received: May 18, 2014. Revised: June 13, 2014.

Published online : September 1, 2014
} 
Several models have been developed to estimate the cost of equity, the most complex part of the cost of capital. In financial theory we distinguish two approaches to estimate the cost of equity: the ex post and ex ante models.

Among the ex post models of estimating the cost of equity, let us mention the CAPM of Sharpe (1964) and Lintner (1965), the APT of Ross (1976), the three-factor pricing model of Fama and French (1993), the ICAPM of Merton (1973), the CCAPM of Breeden (1979), the model of Cox, Ingersoll and Ross (1985), the model of Campbell (1987, 1993), etc. All these models use historical data to estimate the cost of equity and assume that the past relationship between risk and return will continue in the future. The widespread use of ex post models is explained by the fact that the expected returns are not observable. In addition, in an efficient market, the average ex post realized returns should be an unbiased estimator of the expected returns. However, several empirical studies have questioned the relevance of these ex post models. For example, Fama and French (1997) found that estimates of the cost of equity by ex-post models are inevitably imprecise. According to the authors, this inaccuracy is mainly due to the difficulty of identifying the appropriate asset pricing models and to the vagueness in estimating the risk premium determinants.

Among the ex ante models of estimating the cost of equity, let us mention the dividend discount model of Gordon and Shapiro (1956), the residual income model of Edwards and Bell (1961), Peasnell (1982), and Ohlson (1965), Marston and Harris (1993), Ohlson and Juettner-Nauroth (2000), Claus and Thomas (2001), Gebhardt, Lee and Swaminathan (2001), Liu, Nissim and Thomas (2002), Gode and Mohanram (2003), Easton and Monahan (2003), Botosan and Plumlee (2005). The basic idea of the ex-ante models is to use observable forward-looking data instead of historical return realizations. The unobservable expected cost of equity capital is estimated from currently available analysts' consensus forecasts about the firm's future income and its market price. The estimated cost of equity is calculated by equating the current stock price with the intrinsic value of the firm and by solving for the internal rate of return. These ex ante estimation models cost of equity have several disadvantages. Indeed, these estimated costs of equity depend on the underlying model to estimate the intrinsic value. In addition, there are significant biases in analysts' forecasts, the latter having often tend to be particularly optimistic ${ }^{3}$.

There is another type of ex ante models to estimate the implied cost of equity, namely, the option-based model developed by Hsia (1991) and the Market-Derived Capital Pricing Model of McNulty, Yeh, Schulze and Lubatkin (2002). Hsia (1991) builds up on the work of Black and Scholes (1973) that shows the equity of a firm can be valued as a call option using the option-pricing model. However, its implementation requires a number of assumptions that may distort the true value of the firm, such as the debt being similar to a zero coupon bond or the assets of the firm being traded and its price observable, which would allow for arbitrage.

The MCPM is based on financial market instruments, namely bond yields and option prices. Instead of focusing on drawing information on the historical stock-to-market correlation, it tries to derive the information from the options market and yields on government and corporate bonds. Such approach has an advantage over beta since it enables investor to use ex ante data and also give the possibility to derive different rates according to the time period of the investment, compared to a fit-for-all beta.

\footnotetext{
${ }^{3}$ See Han, Manry and Shaw (1996).
} 
Theoretically, the ex ante models appear more relevant than the ex post models in predicting financial assets future prices. Indeed, investors in the financial market are interested in future investment returns and not those of the past. The estimated costs of equity by ex ante models are supposed to reflect, at any given time, the rate of return expected by investors, which is quite consistent with the discounting concept.

The common main shortcoming of the ex ante models is that they do not explicitly take into account the competitive dynamics of the firm when estimating its cost of equity.

The ex ante models are based on the financial market efficiency hypothesis. However, in an efficient financial market, the stock price accurately reflects not only, all available information, but also the combined expectations of investors about the ability of the firm to create value in the future. For its part, the ability to create shareholder value is largely determined by the competitiveness degree of the firm, namely its ability to seize a competitive advantage and to maintain it for a definite period of time, called the competitive advantage period "CAP".

The competitive advantage period concept provides relevant information on the firm's competitive dynamics, as well as its competitive economic equilibrium. According to Saint-Pierre (2002): "The economic equilibrium is an ideal state and not a real state, defining by the limit of a rest position, or an absence of action, the relationships of economic coherency corresponding to any set of given conditions of departure, of which a marginal return on capital greater than the marginal cost of capital is revealing of any competitive advantage."

The examination of these ex ante models shows that they do not take into account the concept of the competitive advantage period when estimating the cost of equity. Indeed, the time horizon during which the firm is supposed to create value is fixed arbitrarily. In addition, it is applied to all firms, regardless of the difference in their competitiveness degree. Therefore, the cost of equity estimated by these models is highly sensitive to changes in this fixed-duration period. In other words, the misunderstanding of the real duration of the firm competitive advantage leads to an estimated cost of capital that is potentially biased. Consequently, the latter will have an impact on the firm valuation, its performance measurement and investment choices.

The aim of the work is to develop a new version of MCPM to estimate the cost of equity by taking into account the competitive advantage of the firm.

Unlike the MCPM of McNulty, Yeh, Schulze and Lubatkin (2002), our dynamic version takes into account the market expectations about the competitive economic equilibrium of the firm. The originality of this version is to integrate, in a dynamic competitive framework, the combined expectations of investors who actually have an influence on the value of the securities, and those of the firm managers leading to competitive economic equilibrium.

Thus, in the dynamic version of the MCPM, the choice of a fixed-duration period corresponds to the time horizon of the disappearance of the competitive advantage of the firm; it is called, the competitive advantage period (CAP). At the CAP of the firm, the marginal performance spread is equal to zero. Thus, at the CAP we obtain the maximum value of economic value added, the firm's continued growth in size no longer adds to its net present value and the average return on capital exceeds the cost of capital which means a positive average performance spread.Therefore, the objective of this research is to (1) develop a dynamic version of MCPM, namely the DMCPM (2) use this new model to estimate the costs of capital of a sample of U.S. firms and (3) empirically test the relevance of costs of capital estimated from the DMCPM compared to those estimated 
from the CAPM.

The remainder of this paper proceeds as follows. Section 2 presents the algorithm of the DMCPM. Section 3 discusses the research hypotheses. Section 4 describes our research methodology including our choice of variables, the sample, the study period, the models to be tested and the descriptive statistics. Empirical findings are reported and analysed in section 5. Finally, section 6 provides a conclusion.

\section{The Algorithm of the DMCPMP}

The DMCPM is developed in a competitive economic equilibrium framework. It is based on the relationship between the marginal cost of capital and the degree of competitiveness of the firm, as measured by the competitive advantage period « CAP» («T »). Precisely, we argue that, under a firm's competitive dynamics, the integration of combined expectations of investors and managers leads to a competitive economic equilibrium, so that the level of a firm's cost of capital and its degree of competitiveness are determined jointly, or even simultaneously. The intersection of the marginal return on investment with the marginal cost of capital determines the competitive economic equilibrium of the firm.

In the DMCPM, we assume that the estimated cost of capital incorporates all available information, including investor expectations about the ability of firms to seize a competitive advantage and to maintain it for a definite period of time corresponding to its competitive advantage period "CAP ".

At the outset, it should be noted that the DMCPM is based on the fact that investors want to be compensated for three types of risk: (1) the macroeconomic risk, (2) the risk of poor corporate governance and (3) the operational risk and the financial risk.

(1) and (2) - The macroeconomic risk and the risk of poor corporate governance:

For the macroeconomic risk, the DMCPM suggests taking the forward rate on government bonds corresponding to the competitive advantage period of the firm "CAP». For the risk of poor corporate governance, the model recommends taking the average rate of return paid by comparable companies (i.e. with the same rating on bonds, for the same « CAP » that the firm under study) or, preferably, the yield to maturity on the bonds of the company itself for a term equals to the « CAP », if it exists.

(3) - The operational and financial risks:

To calculate the operational risk and financial risk, the DMCPM recommends the following steps:

Step \#1: Calculate the forward break-even price of the stock (how well the share price must perform in order to compensate equity investors for their additional risks, knowing that return on equity should be greater than the return on bonds of the subject company and that the current bond yield reflects the specific-company risk of the company).

$R_{e}=R_{g}+R_{d i v}$

with,

$R_{e}:$ Rate of return on equity

$R_{g}:$ Rate of return coming from capital gains

$R_{d i v}$ : Rate of return coming from dividends (dividend yield) 
Since the return on equity must be greater that the return on debt (i.e. that the return coming from capital gains and dividends should be greater than the return on debt), it follows that the minimal rate of return on capital gain that equity investors require on a stock can be no less that the difference between the return on debt and the dividend yield:

$R_{\text {min. } g}=R_{d}-R_{\text {div }}$

With,

$R_{\text {min. } g}:$ Minimal rate of return coming from capital gain

$R_{d}$ : Rate of return on debt, or bond yield

And the forward break-even price is computed as follows:

$F V_{\text {forward break-even price }}=P_{0}\left(1+R_{\text {min.g }}\right)^{T}$

$P_{0}$ equals the current market price of the stock, $\mathrm{T}$ is the "CAP" in years and $F V_{\text {forward break-even price }}$ is the price the subject company stock must reach at the end of the "CAP" to make the minimum rate of return. In other words, the stock price must at a minimum increase from $P_{0}$ to $F V_{\text {forward break-even price }}$ to earn a compound rate of return equal to $\left(R_{d}-R_{\text {div }}\right)$.

After we have obtained the minimum acceptable stock price, we find out how likely it is that a business will fail to reach the target price. We do this by looking at the prices for options on the company, which reflect the market's level of uncertainty about a company's ability to deliver the expected cash flows.

Step \#2: Estimate the stock's expected volatility " $\sigma^{*}$ " using an option pricing model like the Black-Scholes option pricing model to solve for the implied volatility. The Chicago Board Options Exchange (CBOE) will be used to estimate the implied volatility " $\sigma^{*}$ ".

Step \#3: Calculate the cost of the downside insurance. We combine our estimate of volatility with the $F V_{\text {forward break-even price }}$ to determine the price investors would be prepared to pay in order to insure against the chances that the shares will fall below the forward break-even price. This is the premium that reflects the extra risk of equity over debt using, once again, the Black-Scholes option pricing model.

The DMCPM computes the cost of the downside insurance by calculating the value of the theoretical put option with a strike price equals to the forward break-even price (from step $\# 1$ ), an implied volatility (from step \#2), a time to maturity equals to "T", an underlying asset price equals to $\left(P_{0}\right)$, and a risk-free rate " $r$ " .

Step \#4: Derive the annualized excess equity return. This step expresses the dollar cost of the insurance calculated in step \#3 as an annualized rate. This rate is the excess equity return that will be added to the yield on the company's bonds of the appropriate maturity to provide the market based estimate of the cost of equity capital.

$$
\begin{aligned}
& \frac{P_{\text {option put }}}{P_{0}}=(\text { Excess Equity Return })\left[\frac{1-\left(1+R_{d}\right)^{-T}}{R_{d}}\right] \\
& \text { Excess Equity Return }=\frac{P_{\text {option } p u t}}{P_{0}}\left[\frac{R_{d}}{1-\left(1+R_{d}\right)^{-T}}\right]
\end{aligned}
$$

With,

$P_{\text {option put }}$ : Theoretical option put price 
$P_{0}$ : Current market price of the stock

$R_{d}$ : Rate of return on debt, or bond yield

$T$ : "Competitive Advantage Period" of the company (in years)

Step \#5: Combine the bond yield $\left(R_{d}\right)$ with excess equity return (step \#4) to provide the DMCPM estimate of the cost of equity capital.

$$
\text { DMCPM Cost of equity capital }=R_{d}+\text { Excess Equity Return }
$$

The DMCPM cost of equity should be used in the calculation of the marginal cost of capital. Thus, the aim of the DMCPM is to estimate the required rate of return on equity, which explicitly takes into account the uncertainty about the competitive economic equilibrium, the "CAP" of the company under study.

\section{Hypotheses Development}

In this study, we selected two models for estimating the cost of capital, namely, the CAPM (Capital Asset Pricing Model) and the DMCPM (Dynamic Market-Derived Pricing Model). The CAPM is an ex post static model that ignores the competitive dynamics of the firm. On the contrary, the DMCPM is a dynamic ex ante model that takes into account the competitive dynamics of the firm.

A simple comparative analysis of the algorithms of the CAPM and the DMCPM shows that there is an evident difference in the principles and the hypotheses of these two models. Therefore, our first research hypothesis is the following:

Hypothesis 1 (H1): The costs of capital estimated from the CAPM are significantly different from the costs of capital estimated from the DMCPM.

Taking into account the competitive dynamics of the firm in the estimate of its cost of capital, Mouelhi and Saint-Pierre (2013) showed that the marginal return to cost of capital ratio is the relevant value creation indicator in a competitive economic equilibrium framework. Thus, we state our second hypothesis as follows:

Hypothesis 2 (H2): Regarding market value creation, the marginal return to cost of capital ratio from the DMCPM presents more explanatory power than the marginal return to cost of capital ratio from the CAPM.

\section{Research Methodologies: Data, sample, models, and descriptive statistics}

\subsection{Sample Design and Data}

The sample consists of 80 U.S. firms. It includes 10 firms from each of the following eight sectors: Energy, metals and mining, industrials, consumer goods, food and tobacco, health care, utilities, and financials. Since we need to have an approximate measure of the "CAP" of each firm, we have proceeded as follows to select this sample: First, for each sector of the S\&P 500, we have calculated the performance index. Thereafter, we have selected 10 firms from each sector, namely, the first five firms above the median of the performance index (i.e. the ratio of the return on invested capital to the cost of capital 
(from CAPM) and the first five firms below the median of the performance index. In fact, it is reasonable to assume that the 10 firms of each sector are in an economic competitive disequilibrium. This sample design strategy permits us to assume that these firms have a CAP equal to three years, which is a reasonable estimate of their true CAP.

The cross-section data of this study are obtained from Bloomberg, Valueline, Stockpointer and CBOE. For the 80 firms, we have estimated their cost of capital from the CAPM and from the DMCPM at the same point of time, namely the December $31^{\text {st }}$, 2009 and we have done it at this exact date to simulate a real situation.

\subsection{Methodology and Models}

The research methodology involves the following four steps:

- Step 1: For the 80 firms, we estimate the cost of capital from two models, namely, CAPM and DMCPM. The cost of capital from the CAPM is obtained directly from Bloomberg. For the cost of capital from the DMCPM, we first estimate the cost of equity according to the algorithm of this model. Thereafter, we use the other required variables (weights, cost of debt, and cost of preferred stock) available from Bloomberg to estimate the cost of capital.

- Step 2: To test the first hypothesis (H1), we use the three difference tests: the mean difference test (t-test), the median difference test (Wilcoxon test), and the standard deviation difference test (F-test).

- Step 3: To test the second hypothesis (H2), we first examine the correlation coefficients of Pearson and the correlation coefficients of Spearman between the variable that measures the value market creation (MVCAPITAL), and the marginal return to cost of capital ratios from the CAPM (MRCAPM) and from the DMCPM (MRDMCPM). Second, we use the Cox test (1962), and the J test of Davidson and MacKinnon (1981) to statistically compare the explanatory power (i.e. Adjusted R-squared) of the two following cross-section models:

Model 1: $M V C A P I T A L_{i}=\alpha+\beta M R C A P M_{i}+\varepsilon_{i}$

Model 2: $M V C A P I T A L_{i}=\alpha+\beta M R D M C P M_{i}+\varepsilon_{i}$

With,

MVCAPITAL $L_{i}$ : The market value of capital to the beginning capital ratio of the firm $i$.

$M R C A P M_{i} \quad$ : The marginal return of capital to cost of capital ratio from the CAPM of the firm i.

$\operatorname{MRDMCPM}_{i}$ : The marginal return of capital to cost of capital ratio from the DMCPM of the firm i.

\subsection{Descriptive Statistics}

Table 1 reports descriptive statistics of the cost of capital estimated from the DMCPM and those estimated from the CAPM for the overall sample. As we can see, the average of the cost of capital from the DMCPM (10.65\%) is much higher than the average of the cost of capital from the CAPM $(9.01 \%)$. Also, we note that the median and the standard deviation of the cost of capital from the DMCPM (10.62\% and $2.36 \%$, respectively) are much higher than those from the CAPM $(8.89 \%$ and $1.48 \%$, respectively). 
Table 1: Descriptive statistics (overall sample)

\begin{tabular}{lccc}
\hline & Mean & Median & S-D \\
\hline$W A C C_{C A P M}$ & 0.0901 & 0.0889 & 0.0148 \\
$W A C C_{D M C P M}$ & 0.1065 & 0.1062 & 0.0236 \\
\hline $\begin{array}{l}W A C C_{C A P M} \text { is the cost of capital from the CAPM and } \\
\text { capital from the DMCPM }\end{array}$ & & $W A C C_{D M C P M}$ is &
\end{tabular}

Table 2 reports the mean, median, and standard deviation of the cost of capital estimated from the DMCPM and those estimated from the CAPM for the eight sectors. As we can see, the average of the cost of capital from the DMCPM is much higher than the average of the cost of capital from the CAPM for the eight sectors. In addition, for the costs of capital from the MCPM and from CAPM, we note that the consumer sector shows the highest average, and the food and tobacco sector shows the lowest average.

Table 2: Descriptive statistics (by sector)

\begin{tabular}{|c|c|c|c|}
\hline & Mean & Median & S-D \\
\hline \multicolumn{4}{|l|}{ Energy: } \\
\hline$W A C C_{C A P M}$ & 0.0938 & 0.0951 & 0.0106 \\
\hline$W A C C_{D M C P M}$ & 0.1190 & 0.1218 & 0.0184 \\
\hline \multicolumn{4}{|c|}{ Metals and mining: } \\
\hline$W A C C_{C A P M}$ & 0.0952 & 0.0924 & 0.0086 \\
\hline$W A C C_{D M C P M}$ & 0.1068 & 0.1065 & 0.0148 \\
\hline \multicolumn{4}{|c|}{ Food and tobacco: } \\
\hline$W A C C_{C A P M}$ & 0.0782 & 0.0776 & 0.0087 \\
\hline$W A C C_{D M C P M}$ & 0.0908 & 0.0890 & 0.0140 \\
\hline \multicolumn{4}{|l|}{ Health care: } \\
\hline$W A C C_{C A P M}$ & 0.0852 & 0.0853 & 0.0075 \\
\hline $\begin{array}{l}W A C C_{D M C P M} \\
\text { utilities: }\end{array}$ & 0.1017 & 0.1015 & 0.0174 \\
\hline$W A C C_{C A P M}$ & 0.0796 & 0.0794 & 0.0112 \\
\hline$W A C C_{D M C P M}$ & 0.0983 & 0.1001 & 0.0233 \\
\hline \multicolumn{4}{|l|}{ Financials: } \\
\hline$W A C C_{C A P M}$ & 0.0926 & 0.0958 & 0.0211 \\
\hline$W A C C_{D M C P M}$ & 0.1060 & 0.1133 & 0.0232 \\
\hline \multicolumn{4}{|c|}{ Consumer goods : } \\
\hline$W A C C_{C A P M}$ & 0.1008 & 0.1020 & 0.0107 \\
\hline$W A C C_{D M C P M}$ & 0.1197 & 0.1183 & 0.0312 \\
\hline \multicolumn{4}{|l|}{ Industrials: } \\
\hline$W A C C_{C A P M}$ & 0.0958 & 0.0970 & 0.0200 \\
\hline$W A C C_{D M C P M}$ & 0.1100 & 0.1053 & 0,0321 \\
\hline
\end{tabular}

$W A C C_{C A P M}$ is the cost of capital from the CAPM and $W A C C_{D M C P M}$ is the cost of capital from the DMCPM

Table 3 reports the mean, median, and standard deviation of the dependent variable (MVCAPITAL) and of the two explanatory variables (MRCAPM and MRDMCPM). In interpreting the content of Table 3, we suggest to focus on the case of the MRCAPM. As 
expected, this explanatory variable shows the highest mean and median (4.9842 and 2.4313, respectively). In addition, we note that the MRDMCPM shows the highest standard deviation (10.876). Finally, we can conclude that the means, medians and standard deviations of the MRDMCPM and the MRCAPM have almost similar values.

Table 3: Descriptive statistics (dependent variable and explanatory variables)

\begin{tabular}{lccc}
\hline & Mean & Median & S-D \\
\hline MVCAPITAL & 2.1474 & 1.9015 & 1.2707 \\
MRCAPM & 4.9842 & 2.4313 & 9.0593 \\
MRDMCPM & 4.6985 & 1.9774 & 10.876 \\
\hline
\end{tabular}

MVCAPITAL is the market value to the beginning capital ratio (i.e. dependent variable), MRCAPM is the marginal return to cost of capital ratio from the CAPM and MRDMCPM is the marginal return to cost of capital ratio from the DMCPM.

\section{Empirical Analysis and Results}

Table 4 reports the comparison results of the mean, the median, and the standard deviation between the costs of capital from the CAPM and the costs of capital from the DMCPM. The mean difference tests (t-test), the median difference tests (Wilcoxon test) and the standard deviation difference tests (F-test) indicate a significant difference in the mean, the median and the standard deviation at a $1 \%$ significance level. These results show that the costs of capital from the CAPM and those from the DMCPM are significantly different. Thus, we can conclude that hypothesis 1 is accepted.

Table 4: Mean difference tests, median difference tests, and standard deviation difference tests

\begin{tabular}{llcl}
\hline & t-test & Wilcoxon-test & F-test \\
\hline \multirow{2}{*}{$W A C C_{C A P M}$ vs $W A C C_{D M C P M}$} & $-5.249 * * *$ & $4.574 * * *$ & $2.546^{* * *}$ \\
& $(0.000)$ & $(0.000)$ & $(0.000)$ \\
\hline$W A C C_{C A P M}$ is the
\end{tabular}

$W A C C_{C A P M}$ is the cost of capital from the CAPM and $W A C C_{D M C P M}$ is the cost of capital from the DMCPM. (***), (**) and (*) statistically significant at $1 \%, 5 \%$ and $10 \%$, respectively. Numbers in parentheses represent p-values.

Table 5 presents the Pearson correlation coefficients and the Spearman correlation coefficients of the dependent variable which measures the market value creation (MVCAPITAL) and the two explanatory variables (MRCAPM and MRDMCPM). Overall, these results show a significant positive correlation at a $1 \%$ significance level between the MVCAPITAL and the two performance indicators. In interpreting the content of table 5, let us focus on the case of the MRDMCPM. As we can see, this performance indicator shows the highest Pearson correlation coefficient $(72.0 \%)$ and the highest Spearman correlation coefficient (35.8\%), compared to those of the MRCAPM which are equal to $57.3 \%$ and $32.5 \%$, respectively. This means that the positive correlation between the market value creation and the marginal return to cost of capital ratio from the model that takes into account the competitive dynamics of the firm, namely the DMCPM, is higher than the positive correlation between the market value creation 
and the marginal return to cost of capital ratio from the static model, which is the CAPM.

Table 5: Pearson correlation and Spearman correlation coefficients

\begin{tabular}{lcc}
\hline & MRCAPM & MRDMCPM \\
\hline MVCAPITAL & $0.573^{* * *}$ & $0.720^{* * * *}$ \\
$\begin{array}{c}\text { Pearson Coeff. } \\
\text { (p-value) }\end{array}$ & $(0 ., 000)$ & $(0.000)$ \\
MVCAPITAL & & $0.358^{* * *}$ \\
Spearman Coeff. & $0.325^{* * *}$ & $(0.000)$ \\
$\quad$ (p-value) & $(0.000)$ & \\
\hline
\end{tabular}

MVCAPITAL is the market value to the beginning capital ratio (i.e. dependent variable), MRCAPM is the marginal return to cost of capital ratio from the CAPM and MRDMCPM is the marginal return to cost of capital ratio from the DMCPM. (***), (**) and (*) statistically significant at $1 \%, 5 \%$ and $10 \%$, respectively. Numbers in parentheses represent $\mathrm{p}$-values.

Table 6 reports the results of cross-sectional regressions of the MVCAPITAL on the MRCAPM and the MRDMCPM. The results show that the two regressions have a positive and statistically significant coefficient at a $1 \%$ significance level. Such results support the theoretical framework of Mouelhi and Saint-Pierre (2013) which states a positive relationship between the market value creation and the marginal return to cost of capital ratio.

Table 6: Cross-sectional regressions of MVCAPITAL on MRCAPM and MRDRIM

\begin{tabular}{|c|c|c|c|c|c|c|}
\hline & & Constant & MRCAPM & MRDMCPM & R2-adjusted & F-statistic \\
\hline Model & 1 & $\begin{array}{l}1.7465 * * * \\
(0.000)\end{array}$ & $\begin{array}{l}0.0804^{* * * *} \\
(0.000)\end{array}$ & - & $32.01 \%$ & $\begin{array}{r}38.20 \\
(0.000)\end{array}$ \\
\hline Model & 2 & $\begin{array}{l}1.7520 * * * \\
(0.000)\end{array}$ & - & $\begin{array}{l}0.0841 \text { *** } \\
(0.000)\end{array}$ & $51.25 \%$ & $\begin{array}{r}84.06 \\
(0.000)\end{array}$ \\
\hline
\end{tabular}

MVCAPITAL is the market value to the beginning capital ratio (i.e. dependent variable), MRCAPM is the marginal return to cost of capital ratio from the CAPM and MRDMCPM is the marginal return to cost of capital ratio from the DMCPM. (***), (**) and $(*)$ statistically significant at $1 \%, 5 \%$ and $10 \%$, respectively. Numbers in parentheses represent p-values.

The comparative analysis of the explanatory power between the MRCAPM and the MRDMCPM will be tested mainly by the comparison of the R2 (adjusted) of the two cross-sectional regressions (Model 1 and Model 2). The results reported in the fifth column of Table 6 indicate that the highest R2-adjusted is obtained from the regression of the MVCAPITAL on the MRDMCPM, namely 51.25\%, whereas the R2-adjusted obtained from the regression of the MVCAPITAL on the MRCAPM is equal to $32.01 \%$.

Table 7 presents the results of the Cox test (Cox $(1961,1962))$. Recall that the Cox test is used to test the statistical significance of the difference between two R2-adjusted. In other words, it is used to test the statistical significance of the difference in the explanatory 
power between the MRCAPM and the MRDMCPM. In interpreting the content of Table 7, let us focus on the result of the MRCAPM versus the MRDMCPM test. As we can see, the p-value is equal to 0.006 which indicates the rejection of the sub-null hypothesis that the model with the MRCAPM as an explanatory variable is preferable to the model with the MRDMCPM as an explanatory variable. In addition, we can notice that the p-value of the MRDRIM versus the MRCAPM test is equal to 0.132 , which indicates the non-rejection of the inverse sub-null hypothesis that the model with the MRDMCPM as an explanatory variable is preferable to the model with the MRCAPM as an explanatory variable. Overall, the results of the Cox test show that the MRDMCPM has a statistically significantly higher explanatory power regarding the market value creation than the MRCAPM.

Table 7: Cox tests results

\begin{tabular}{cccc}
\hline \multicolumn{2}{c}{$H_{0}:$ MRCAPM vs MRDMCPM } & \multicolumn{1}{c}{$H_{0}:$ MRDMCPM vs MRCAPM } \\
\hline Cox-stat & -2.391 & Cox-stat & -1.116 \\
$($ p-value $)$ & $(0.006)$ & (p-value) & $(0.132)$ \\
\hline
\end{tabular}

MRCAPM is the marginal return to cost of capital ratio from the CAPM and MRDMCPM is the marginal return to cost of capital ratio from the DMCPM. Numbers in parentheses represent $\mathrm{p}$-values.

Table 8 reports the results of the $\mathrm{J}$ test. As we can see, the p-value of the coefficient " $\lambda$ " ( 0.3927$)$ does not reject the null hypothesis ( $\mathrm{p}$-value=0.368). This means that the model with the MRDMCPM as an explanatory variable is preferable to the model with the MRCAPM as an explanatory variable. This result confirms that the MRDMCPM has a statistically significantly higher explanatory power regarding the market value creation than the MRCAPM. According to the results of the Cox test and the J test, we can notice that the marginal return to cost of capital ratio from the dynamic model, namely the DMCPM has a statistically significantly higher explanatory power regarding the market value creation than the marginal return to cost of capital ratio from the static model, which is the CAPM. Thus, we can conclude that hypothesis 2 is accepted.

Table 8: J tests results

\footnotetext{
$H_{0}: \lambda=0$ (The model with « $\mathrm{X} »$ as explanatory variable is preferable to the model with $« \mathrm{Z} »$ as explanatory variable)

$H_{1}: \quad \lambda \neq 0 \quad$ (The model with « $\mathrm{Z}$ » as explanatory variable is preferable to the model with « $\mathrm{X} »$ as explanatory variable)
}

$\lambda$

(p-value)

$\mathrm{X}: \mathrm{MRDMCPM}$

\section{$\mathrm{Z}:$ MRCAPM}

MRCAPM is the marginal return to cost of capital ratio from the CAPM and MRDMCPM is the marginal return to cost of capital ratio from the DMCPM. (***), (**) and (*) statistically significant at $1 \%, 5 \%$ and $10 \%$, respectively. Numbers in parentheses represent p-values. 


\section{Conclusion}

In a highly competitive and increasingly dynamic economic environment, it is more and more important to accurately estimate the cost of equity, and, subsequently, the cost of capital of the firm. Several researches over the last decades were concerned with the development of models to estimate the firm's cost of equity. We distinguish two broad categories: the ex post models and the ex ante models. However, these models do not take into account the concept of the competitive advantage period (CAP) when estimating the cost of equity. To the best of our knowledge, no study has proposed to estimate a cost of capital that reflects the competitive dynamics of the firm. In this study, we have proposed a dynamic version of the Market-Derived Capital Pricing Model of McNulty, Yeh, Schulze and Lubatkin (2002).

In a competitive economic equilibrium framework, we have developed a Dynamic Market-Derived Capital Pricing Model (DMCPM) by introducing the competitive advantage period (CAP) in the estimation process of the firm's cost of equity. Thus, in the DMCPM, the choice of fixed-duration period corresponds to the CAP of the firm. (i.e. how long it will take for the disappearance of the competitive advantage of the firm)

In this study, we have used a cross section data of a sample of 80 U.S. firms, which are most likely in a dynamic equilibrium setting for testing our research hypotheses. Firstly, we have tested the difference of the mean, the median, and the standard deviation between the costs of capital from the DMCPM and the costs of capital estimated from the CAPM, as an ex post static model. The results of difference tests (t-test, Wilcoxon test, and F-test) have showed that the costs of capital from the DMCPM and those from the CAPM are significantly different.

Secondly, based on the paper of Mouelhi and Saint-Pierre (2013), in which the authors have shown that the marginal return to cost of capital ratio is the relevant value creation indicator in a competitive economic equilibrium framework, we have tested the explanatory power of the marginal return to cost of capital ratio from the DMCPM versus the explanatory power of the marginal return to cost of capital ratio from the CAPM. The results of the correlation coefficients of Pearson and the correlation coefficients of Spearman have showed that the positive correlation between the market value creation (MVCAPITAL) and the marginal return to cost of capital ratio from the DMCPM, is higher than the positive correlation between the market value creation and the marginal return to cost of capital ratio from the CAPM. In addition, the results of cross-sectional regressions, the Cox test, and the $\mathrm{J}$ test have showed that the marginal return to cost of capital ratio from the DMCPM has a statistically significantly higher explanatory power regarding the market value creation than the marginal return to cost of capital ratio from the CAPM.

These results confirm the robustness of the DMCPM as an ex ante model that take into account the concept of the competitive advantage period when estimating the cost of equity. In fact, in our dynamic version of the Market-Derived Capital Pricing Model, the time horizon during which the firm is supposed to create value is not fixed arbitrarily. In the DMCPM, our sample design permits us to assume that these firms have a CAP equal to three years, which is a reasonable estimate of their true CAP. Thus, the estimated costs of capital from the DMCPM are, necessarily, unbiased and more relevant in the firm valuation, its performance measurement and investment choices.

These are the main results of this study, The results could be more robust, if we had included a larger number of firms in the sample and if we had treated a panel data instead 
of the cross-sectional data. In addition, the empirical study that includes other static models, such as the Fama and French three-factor model, and the Ross arbitrage model, could be interesting for future research.

\section{References}

[1] A. Ando and A.J. Auerbach, "The cost of capital in the United States and Japan: A comparison", Journal of Japanese and international Economies, 2, 1988, pp.134-158.

[2] A. Ando and A.J. Auerbach. "The cost of capital in Japan: Recent evidence and further results", Journal of Japanese and international Economies, 4, 1990, pp. 323-350.

[3] J.B. Berk, R.C. Green and V. Naik, "Optimal investment, growth options, and security returns", Journal of Finance, 54(5), 1999, pp. 1553-1607.

[4] M.A. Berry, E. Burmeister and M.B. McElroy, "Sorting out risks using known APT factors", Financial Analysts Journal, 44, 1988, pp. 29-42.

[5] D. Besanko, D. Dranove and M. Shanley, "The economics of strategy", John Wiley \& Sons, Inc., New York, 1996.

[6] F. Black and M. Scholes, "The pricing of options and corporate liabilities", Journal of Political Economy, May-June, 1973, pp. 637-659.

[7] F. Black, "Beta and return", Journal of Portfolio Management, 20, 1993, pp. 8-18.

[8] F. Black, M.C. Jensen and M. Scholes, "The capital asset pricing model: Some empirical tests", in Jensen, M.C., ed., Studies in the Theory of Capital Markets, Praeger, 1972.

[9] D.T. Breeden, "An inter-temporal asset pricing model with stochastic consumption and investment opportunities", Journal of Financial Economics, 7, 1979, pp. 265-296.

[10] J.Y. Campbell, "Intertemporal asset pricing without consumption data", American Economic Review, 83, 1993, pp. 487-512.

[11] M.D. Carlson, A.J. Fisher and R. Giammarino, "Corporate investment and asset price dynamics: Implications for the cross-section of returns", Journal of Finance, 59, 2004, pp. 2577-2603.

[12] D.R. Cox, "Tests of separate families of hypotheses", Proceedings of the fourth Berkeley symposium on mathematical statistics and probability, 1, 1961, pp. 105-123.

[13] D.R. Cox, "Further results on tests of separate families of hypotheses", Journal of Royal Statistical Society, 24, 1962, pp. 406-424.

[14] J. Cox, J. Ingersoll and S. Ross, "An intertemporal general equilibrium model of asset prices”, Econometrica, 53, 1985, pp. 363-384.

[15] R. Davidson and J.G. MacKinnon, "Several tests for model specification in the presence of alternative hypotheses", Econometrica, 49, 1981, pp. 781-793.

[16] P. Dechow, A. Hutton and R. Sloan, "An empirical assessment of the residual income model", Journal of Accounting and Economics, 26, 1999, pp. 1-34.

[17] R.A. Dye and S. Sridhar, "Resource allocation effects of price reactions to disclosures", Contemporary Accounting Research, 19(3), Fall, 2002, pp. 385-410.

[18] P. Easton, "Forecasts of earnings and earnings growth, PEG ratios, and the implied internal rate of return on investments in stocks", Working Paper, Ohio State University, 2001.

[19] P. Easton, "Use of forecasts of earnings to estimate and compare cost of capital across regimes", Journal of Business Finance and Accounting, 33(3), 2006, pp. 374-394. 
[20] E. Edwards and P. Bell, "The theory and measurement of business income". Berkeley, CA, University of California Press, 1961.

[21] E.F. Fama and K.R. French, "Size and book to market factors in earnings and returns", Journal of Finance, 50, 1995, pp. 131-155.

[22] L. Gebhardt, C. Lee and B. Swaminathan, "Toward an implied cost of capital", Journal of Accounting Research, 39, 2001, pp. 135-176.

[23] D. Gode and P. Mohanram P, "Inferring the cost of capital using the Ohlson- Juettner Model", Review of Accounting Studies, 8, 2003, pp. 399-431.

[24] M.H. Goedhart, T.M. Koller and Z.D. Williams, "The real cost of equity", McKinsey on Finance, Autumn, 2002.

[25] W. Greene, "Econometrics Analysis", 5 ${ }^{\text {th }}$ edition, Prentice Hall, 2003.

[26] W. Guay, S. Kothari and S. Shu, "Properties of implied cost of capital using analysts' forecasts", Working Paper, University of Pennsylvania, Wharton School, 2005.

[27] H. Guo, "A rationale pricing explanation for the failure of the CAPM", Federal Reserve Bank of St.Louis Review, 86(3), May/June, 2004, pp. 23-33.

[28] B. Han, D. Manry and W. Shaw, "Earnings Uncertainty and the Market Response to Predictable Bias in Analysts' Forecasts", Working paper, Florida International University, 1996.

[29] R.S. Harris, F.C. Marston, D.R. Mishra and T. O'Brien, "Ex ante cost of equity estimates of S\&P 500 firms: The choice between global and domestic CAPM", Financial Management, 32(3), Autumn, 2003.

[30] C. Hsia, "Estimating a firm's cost of capital: An option pricing approach", Journal of Business Finance \& Accounting, January, 18(2), 1991, pp. 281-287.

[31] R. Jagannathan and Z. Wang, "The conditional CAPM and the cross section of expected returns", Journal of Finance, 51(1), 1996, pp. 3-53.

[32] J. Lintner, "The valuation of risk assets and the selection of risky investments in stock portfolios and capital budgets", Review of Economics and Statistics, 47, 1965, pp.13-37.

[33] J.G. MacKinnon, "Model specification tests against non-nested alternatives", Working Paper, Queen's Economics Department, 1983.

[34] R.N. McCauley and S.A. Zimmer, "Explaining international differences in the cost of capital", Federal Reserve Bank of New York Quarterly Review, 14(2), Summer, 1989, pp. 7-28.

[35] J. McNulty, T. Yeh, W. Schulze and M. Lubatkin, "What is your real cost of capital?", Harvard Business Review, October, 2002, pp. 114-121.

[36] D.R. Mishra, "Inferring cost of equity using firm characteristics: A Canadian perspective", Working Paper, ASAC, 2004.

[37] F. Modigliani and M. Miller, "The cost of capital, corporation finance, and the theory of investment", American Economic Review, 48(3), June, 1958, pp. 261-297.

[38] C. Mouelhi and J. Saint-Pierre, "Under the Competitive Dynamics of the Firm: Which Value Creation Indicator is the Most Relevant? “, Journal of Academy of Business and Economics, 13(1), 2013, pp. 35-50.

[39] J. Ohlson, "Earnings, book value, and dividends in security valuation", Contemporary Accounting Research, 11, 1995, pp. 661-687.

[40] J. Ohlson and B. Juettner-Nauroth, "Expected EPS and EPS growth as determinants of value", Working Paper, New York University, 2000.

[41] D. Pecaut, "Canada's high cost of capital: A barrier to investing for the future", Canadian Investment Review, Summer, 1993, pp. 9-16. 
[42] J. Pointon and A. El-Masry, "Competitive advantage and the cost of equity in international shipping”, Journal of the Research Society, 58, 2007, pp. 1138-1145.

[43] M.E. Porter, "Competition in global industries", Harvard Business Press, 1986.

[44] J.M. Poterba, "Comparing the cost of capital in the United States and Japan: A survey of methods", Federal Reserve Bank of New York Quarterly Review, Winter, 1991, pp. 20-32.

[45] S.A. Ross, "The arbitrage theory of capital pricing", Journal of Economic Theory, 13, 1976.

[46] S.A. Ross, "The Capital Asset Pricing Model (CAPM), short-sale restrictions and related issues", Journal of Finance, 32(2), 1977, pp. 177-190.

[47] J. Saint-Pierre, "Management stratégique et valeur intrinsèque de l'entreprise: Introduction au schéma de création de valeur (SCV)", Document de Travail, Université Laval, 1999.

[48] J. Saint-Pierre, "Integration of Net Present Value (NPV), Economic Value Added (EVA), and Free Cash Flows (FCF)", Working paper, Laval University, 2000.

[49] J. Saint-Pierre, "Modèle d'équilibre dynamique des actifs financiers: Théorie et application", Document de Travail, Université Laval, 2002.

[50] W.F. Sharpe, "Capital asset prices: A theory of market equilibrium under conditions of risk", Journal of Finance, 19(3), 1964, pp. 425-442.

[51] J. Witmer and L. Zorn, "Estimating and comparing the implied cost of equity for Canadian and U.S. firms", Working Paper, Bank of Canada, 2007. 